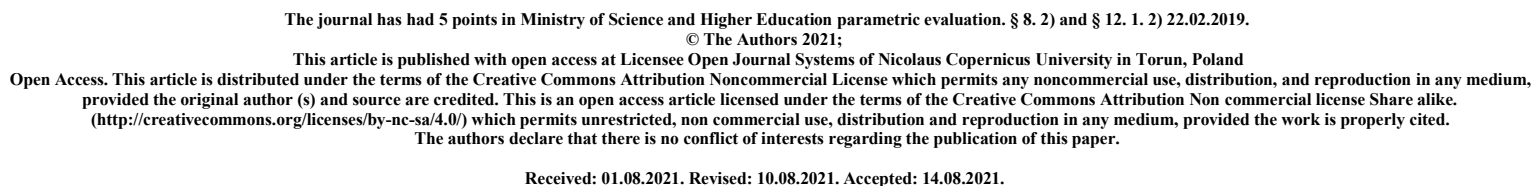

\title{
Adverse Childhood Experiences and worsened social relationships in adult life among Polish medical and dental students
}

\author{
Paulina Drożak ${ }^{1}$, Piotr Duda ${ }^{1}$, Katarzyna Augustowska ${ }^{1}$, Martyna Drożak ${ }^{1}$, \\ Lukasz Bryliński', Agata Bura ${ }^{1}$, Ewa Rudnicka-Drożak ${ }^{2}$
}

1. Students' Scientific Association of Chair and Department of Family Medicine, Medical University of Lublin.

2. Chair and Department of Family Medicine, Medical University of Lublin.

\begin{abstract}
Introduction and purpose. Adverse Childhood Experiences (ACEs) are potentially traumatic events experienced before the age of 18 that have lasting negative effects on physical and mental health. Numerous studies have shown that exposure to Adverse Childhood Experiences increases the probability of chronic health conditions, such as obesity, diabetes, coronary heart disease, asthma, depression or PTSD. The aim of the study was to investigate the prevalence of Adverse Childhood Experiences among medical and dental students of Polish Medical Universities and to examine an association between ACEs and chosen factors associated with social relationships of the students.
\end{abstract}

Material and method. A total of 1162 medical and dental students from each year of education and 18 different Polish universities took part in the study. The research tool 
contained the Adverse Childhood Experiences standardized questionnaire and authors' questions.

Results. More than a half of the students (57.4\%) had at least 1 exposure to ACEs. $8.43 \%$ of them experienced 4 or more childhood adversities. The most commonly reported ACEs were: emotional neglect (23.06\%), emotional abuse (22.98\%) and mental illness or a suicide attempt in a household member (21.86\%). An overall graded relationship was found between ACE score and: parents' lower level of education, negative relationship with parents, siblings and friends and having a diagnosis of depression.

Conclusions. Adverse Childhood Experiences are common among Polish medical and dental students and are associated with worsened social relationships and depression in adult life of the students. It is important to implement strategies that aim to prevent ACEs and help to build social support networks for those that are affected by them.

Key words: Adverse Childhood Experiences; medical students; dental students.

\section{Introduction}

Adverse Childhood Experiences (ACEs) are potentially traumatic events experienced before the age of 18 that have lasting negative effects on physical and mental health. ACEs have been classified into 10 categories and grouped into 3 domains: abuse (physical, emotional and sexual), neglect (physical and emotional) and household dysfunction (mental illness in a household member, domestic violence, parental separation or divorce, incarceration of a household member, substance abuse in a household member) $[1,2]$.

Exposure to ACEs is associated with poorer health outcomes, health risk behaviors and socioeconomic challenges [3]. Numerous studies have shown that exposure to Adverse Childhood Experiences increases the probability of chronic health conditions, such as overweight or obesity, diabetes, coronary heart disease, stroke, asthma, chronic obstructive pulmonary disease and mental disorders, such as depression or PTSD [3, 4, 5, 6, 7]. Moreover, there is a significant correlation between ACEs and formal diagnosis for ASPD [8]. It has also been proven that the experience of ACEs is associated with risky drinking, current smoking, drug abuse, early sexual intercourse and multiple sexual partners [3, 9]. What is more, there is 
a relationship between exposure to ACEs and lower educational attainment or increased probability of being unemployed or unable to work $[3,10,11]$.

Despite the existence of numerous studies about the harmful impact of ACEs on physical and mental health, an analysis conducted among the medical staff of Mercy Health hospital in the USA showed that the majority (80,5\%) of physicians reported having no knowledge of the ACE questionnaire and just 3,5\% of physicians reported having used the ACE questionnaire in their clinical practice $[1,3,12]$. Furthermore, a research conducted among students from the medical school on the West Coast of the USA showed that more than half $(52 \%)$ of the students experienced at least one ACE [13].

\begin{abstract}
Aim
The aim of the study was to investigate the occurrence of Adverse Childhood Experiences among medical and dental students of Polish Medical Universities and to examine an association between ACEs and chosen factors associated with social relationships of the students.
\end{abstract}

\title{
Material and method
}

The research tool consisted of the Adverse Childhood Experiences standardized questionnaire and authors' questions in order to analyze sociodemographic traits of a group put into investigation. The survey contained only single-choice and closed questions that were measured with Likert scale. The participation in the study was anonymous and voluntary. The questionnaires were published through Facebook social media platform on official groups aimed towards medical and dental students of Polish Medical Universities. The data was collected during April of 2020 and analyzed statistically. The Chi-square test of independence, with the level of significance set at $p<0.05$, was used to examine a relationship between the two variables. 


\section{Results}

Demographic characteristics of an investigated group

The research was carried out among 1162 participants. Women constituted of $76.33 \%$ of the respondents $(\mathrm{n}=887)$ and men $-23.67 \%(\mathrm{n}=275)$. The age of the participants ranged from 18 to 34 years, the mean age was $21.71 \pm 1.97$ years, whereas the median age 21 years. $80.38 \%$ of them were medical students $(\mathrm{n}=934)$ and $19.62 \%$ of them were dental students ( $\mathrm{n}$ $=228$ ). Among respondents there were students from each year of both medical and dental studies, from all of the 18 Polish universities that offer medical education and all of the 10 Polish universities that offer dental education. $43.20 \%(\mathrm{n}=502)$ of the students stated that they often feel lonely. $47.07 \%(n=547)$ of the students rated their academic performance positively. $60.07 \%(\mathrm{n}=698)$ of the respondents didn't have problems with maintaining stable body weight. $48.62 \%(n=565)$ of the participants stated that they don't reach for alcohol in order to de-stress or discharge negative emotions. $44.66 \%(n=519)$ of the students described themselves as religious. (Table 1).

Table 1. Demographic data of the participants.

\begin{tabular}{|c|l|}
\hline & n (\%) \\
\hline Course of study & \\
Medicine & $934(80.38 \%)$ \\
Dental medicine & $228(19.62 \%)$ \\
\hline Gender & $887(76.33 \%)$ \\
Female & $275(23.67 \%)$ \\
\hline Mother's level of education & \\
Primary/ Lower secondary/ Basic & $121(10.41 \%)$ \\
vocational & $205(17.64 \%)$ \\
Upper secondary & $836(71.94 \%)$ \\
\hline Higher & \\
Primary/ Lower secondary/ Basic & $301(25.90 \%)$ \\
vocational & $210(18.07 \%)$ \\
\hline Upper secondary & \\
\hline
\end{tabular}




\begin{tabular}{|c|c|}
\hline Higher & $651(56.02 \%)$ \\
\hline \multicolumn{2}{|l|}{$\begin{array}{l}\text { How do you assess your relationship with } \\
\text { your mother? }\end{array}$} \\
\hline Very good/ Good & $915(79.43 \%)$ \\
\hline Average & $180(15.63 \%)$ \\
\hline Bad/ Very bad & $57(4.95 \%)$ \\
\hline \multicolumn{2}{|l|}{$\begin{array}{l}\text { How do you assess your relationship with } \\
\text { your father? }\end{array}$} \\
\hline Very good/ Good & $668(60.02 \%)$ \\
\hline Average & $278(24.98 \%)$ \\
\hline Bad/ Very bad & $167(15.00 \%)$ \\
\hline \multicolumn{2}{|l|}{$\begin{array}{l}\text { How do you assess your relationship with } \\
\text { your siblings? }\end{array}$} \\
\hline Very good/ Good & $717(74.38 \%)$ \\
\hline Average & $191(19.81 \%)$ \\
\hline Bad/ Very bad & $56(5.81 \%)$ \\
\hline \multicolumn{2}{|l|}{$\begin{array}{l}\text { How do you assess your relationship with } \\
\text { your friends? }\end{array}$} \\
\hline Very good/ Good & $891(77.21 \%)$ \\
\hline Average & $223(19.23 \%)$ \\
\hline Bad/ Very bad & $40(3.47 \%)$ \\
\hline \multicolumn{2}{|l|}{ Do you have diagnosed depression? } \\
\hline Yes & $148(12.74 \%)$ \\
\hline No & $1014(87.26 \%)$ \\
\hline
\end{tabular}

\section{Adverse Childhood Experiences}

The results of the Adverse Childhood Experiences questionnaire ranged from 0 to 8 with a mean score of 1.23 and median which equaled 1 (interquartile range $0-2$ ). $42.60 \%$ of the students $(\mathrm{n}=495)$ didn't experience any childhood adversity, $24.53 \%(\mathrm{n}=285)$ were affected by 1 childhood adversity, $14.89 \%(n=173)$ reported an exposure to 2 childhood adversities, 9.55\% $(\mathrm{n}=111)-3$ childhood adversities and 8.43\% $(\mathrm{n}=98)-4$ or more childhood adversities. Overall, more than a half $(\mathrm{n}=667,57.40 \%, 95 \% \mathrm{CI}=54.95-59.85)$ of the participants of the study experienced at least 1 childhood adversity. (Chart 1). The most common adverse childhood experiences were: emotional neglect $(23.06 \%, \mathrm{n}=268)$, 
emotional abuse $(22.98 \%, \mathrm{n}=267)$ and mental illness or a suicide attempt in a household member $(21.86 \%, \mathrm{n}=254) .20 .40 \%(\mathrm{n}=237)$ of the participants had a household member who abused substances. $16.35 \%(\mathrm{n}=190)$ of the students were affected by parental separation or divorce. $7.66 \%(n=89)$ of the respondents experienced physical abuse. $3.7 \%(n=43)$ of the participants of the study were affected by sexual abuse. $3.53 \%(n=41)$ of the participants witnessed violence towards their mother or step-mother. $1.72 \%(n=20)$ of the students reported being physically neglected. $1.55 \%(\mathrm{n}=18)$ of the respondents had a household member who became imprisoned.

Chart 1. Prevalence of the number of Adverse Childhood Experiences among Polish medical and dental students.

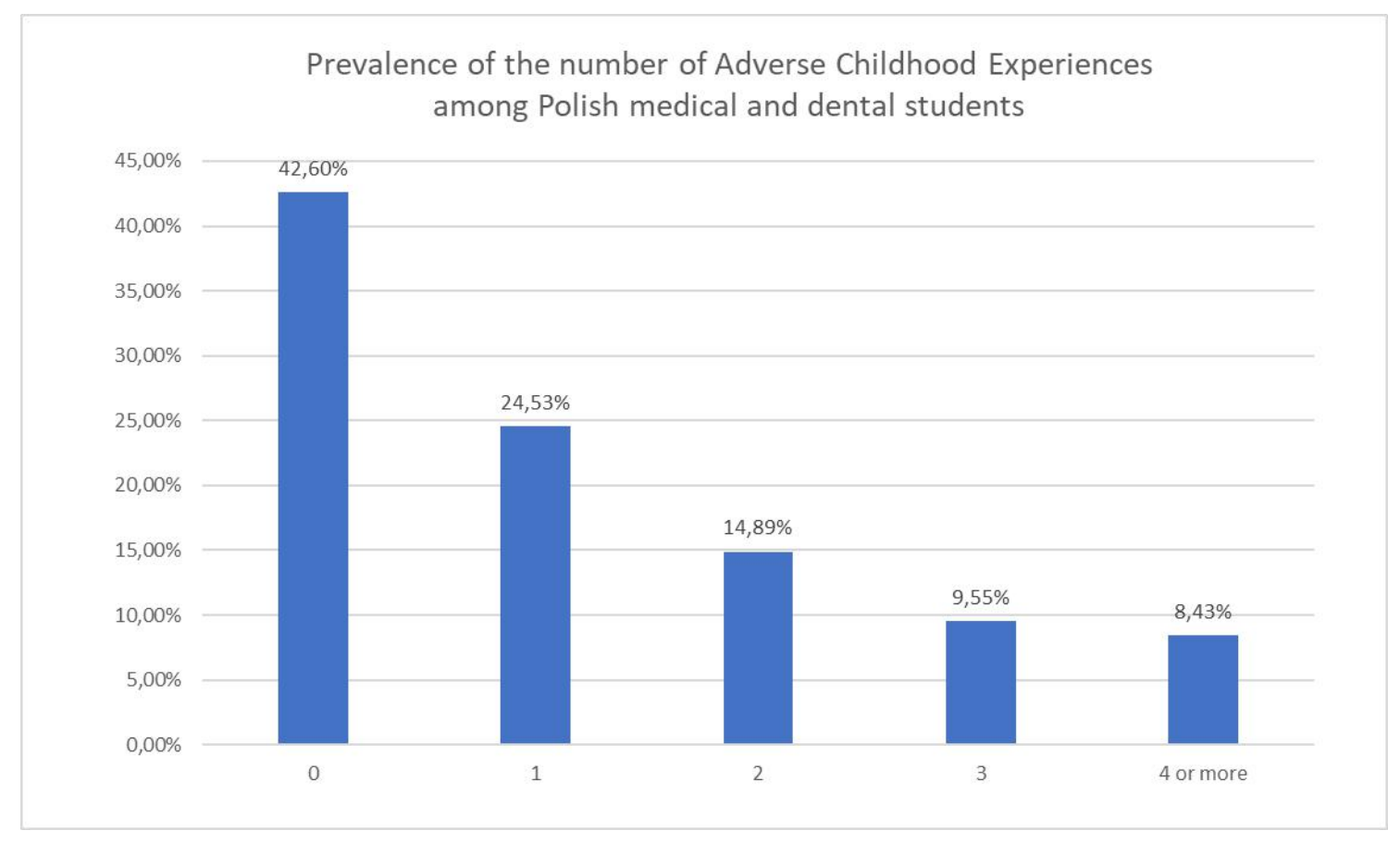

Factors associated with Adverse Childhood Experiences

A relationship was found between Adverse Childhood Experiences and: mother's lower level of education, father's lower level of education, negative relationship with mother, negative relationship with father, negative relationship with siblings, negative relationship with friends and having a diagnosis of depression $(\mathrm{p}<0.05)$. (Table 4$)$. 
Table 4. Adverse Childhood Experiences and factors associated with social relationships.

\begin{tabular}{|c|c|c|c|c|c|c|}
\hline & \multicolumn{5}{|c|}{ Number of ACEs n (\%) } & \multirow{2}{*}{$\begin{array}{l}\text { Statistical } \\
\text { analysis }\end{array}$} \\
\hline & $\mathbf{0}$ & 1 & 2 & 3 & 4 or more & \\
\hline $\begin{array}{l}\text { Mother's level of } \\
\text { education } \\
\text { Primary/ Lower } \\
\text { secondary/ Basic } \\
\text { vocational } \\
\text { Upper secondary } \\
\text { Higher }\end{array}$ & $\begin{array}{l}47(9.49 \%) \\
70(14.14 \%) \\
378 \\
(76.36 \%)\end{array}$ & $\begin{array}{l}23(8.07 \%) \\
58(20.35 \%) \\
204 \\
(71.58 \%)\end{array}$ & $\begin{array}{l}19(10.98 \%) \\
48(27.75 \%) \\
106 \\
(61.27 \%)\end{array}$ & $\begin{array}{l}18(16.22 \%) \\
15(13.51 \%) \\
78(70.27 \%)\end{array}$ & $\begin{array}{l}14(14.29 \%) \\
14(14.29 \%) \\
70(71.43 \%)\end{array}$ & $\begin{array}{c}\chi^{2}=27.43 \\
\mathrm{df}=8 \\
\mathrm{p}=0.0006\end{array}$ \\
\hline $\begin{array}{l}\text { Father's level of } \\
\text { education } \\
\text { Primary/ Lower } \\
\text { secondary/ Basic } \\
\text { vocational } \\
\text { Upper secondary } \\
\text { Higher }\end{array}$ & $\begin{array}{l}120 \\
(24.24 \%) \\
74(14.95 \%) \\
301 \\
(60.81 \%)\end{array}$ & $\begin{array}{l}73(25.61 \%) \\
50(17.54 \%) \\
162 \\
(56.84 \%)\end{array}$ & $\begin{array}{l}53(30.64 \%) \\
35(20.23 \%) \\
85(49.13 \%)\end{array}$ & $\begin{array}{l}31(27.93 \%) \\
25(22.52 \%) \\
55(49.55 \%)\end{array}$ & $\begin{array}{l}24(24.29 \%) \\
26(26.53 \%) \\
48(48.98 \%)\end{array}$ & $\begin{array}{c}\chi^{2}=15.76 \\
\text { df }=8 \\
p=0.04\end{array}$ \\
\hline $\begin{array}{l}\text { How do you assess your } \\
\text { relationship with your } \\
\text { mother? } \\
\text { Very good/ Good } \\
\text { Average } \\
\text { Bad/ Very bad }\end{array}$ & $\begin{array}{l}447 \\
(90.49 \%) \\
39(7.89 \%) \\
8(1.62 \%)\end{array}$ & $\begin{array}{l}228 \\
(80.57 \%) \\
48(16.96 \%) \\
7(2.47 \%)\end{array}$ & $\begin{array}{l}121 \\
(71.60 \%) \\
37(21.89 \%) \\
11(6.51 \%)\end{array}$ & $\begin{array}{l}60(54.55 \%) \\
33(30.00 \%) \\
17(15.45 \%)\end{array}$ & $\begin{array}{l}59(61.46 \%) \\
23(23.96 \%) \\
14(14.58 \%)\end{array}$ & $\begin{array}{c}\chi^{2}=121.66 \\
\mathrm{df}=8 \\
\mathrm{p}=0\end{array}$ \\
\hline $\begin{array}{l}\text { How do you assess your } \\
\text { relationship with your } \\
\text { father? } \\
\qquad \begin{array}{l}\text { Very good/ Good } \\
\text { Average } \\
\text { Bad/ Very bad }\end{array}\end{array}$ & $\begin{array}{l}388 \\
(80.00 \%) \\
83(17.11 \%) \\
14(2.89 \%)\end{array}$ & $\begin{array}{l}156 \\
(57.99 \%) \\
80(29.74 \%) \\
33(12.27 \%)\end{array}$ & $\begin{array}{l}69(42.07 \%) \\
53(32.32 \%) \\
42(25.61 \%)\end{array}$ & $\begin{array}{l}36(33.96 \%) \\
34(32.08 \%) \\
36(33.96 \%)\end{array}$ & $\begin{array}{l}19(21.35 \%) \\
28(31.46 \%) \\
42(47.19 \%)\end{array}$ & $\begin{array}{c}\chi^{2}=244.98 \\
d f=8 \\
p=0\end{array}$ \\
\hline $\begin{array}{l}\text { How do you assess your } \\
\text { relationship with your }\end{array}$ & & & & & & $\begin{array}{c}\chi^{2}=51.47 \\
\text { df }=8\end{array}$ \\
\hline
\end{tabular}




\begin{tabular}{|c|c|c|c|c|c|c|}
\hline $\begin{array}{l}\text { siblings? } \\
\qquad \begin{array}{l}\text { Very good/ Good } \\
\text { Average } \\
\text { Bad/ Very bad }\end{array}\end{array}$ & $\begin{array}{l}346 \\
(83.19 \%) \\
60(14.42 \%) \\
10(2.40 \%)\end{array}$ & $\begin{array}{l}174 \\
(74.68 \%) \\
40(17.17 \%) \\
19(8.15 \%)\end{array}$ & $\begin{array}{l}94(67.14 \%) \\
39(27.86 \%) \\
7(5.00 \%)\end{array}$ & $\begin{array}{l}53(58.24 \%) \\
27(29.67 \%) \\
11(12.09 \%)\end{array}$ & $\begin{array}{l}50(59.52 \%) \\
25(29.76 \%) \\
9(10.71 \%)\end{array}$ & $\mathrm{p}=0$ \\
\hline $\begin{array}{l}\text { How do you assess your } \\
\text { relationship with your } \\
\text { friends? } \\
\qquad \text { Very good/ Good } \\
\text { Average } \\
\text { Bad/ Very bad }\end{array}$ & $\begin{array}{l}410 \\
(83.33 \%) \\
71(14.43 \%) \\
11(2.24 \%)\end{array}$ & $\begin{array}{l}218 \\
(77.03 \%) \\
50(17.67 \%) \\
15(5.30 \%)\end{array}$ & $\begin{array}{l}126 \\
(72.83 \%) \\
43(24.86 \%) \\
4(2.31 \%)\end{array}$ & $\begin{array}{l}68(61.82 \%) \\
37(33.64 \%) \\
5(4.55 \%)\end{array}$ & $\begin{array}{l}69(71.88 \%) \\
22(22.92 \%) \\
5(5.21 \%)\end{array}$ & $\begin{array}{c}\chi^{2}=34.86 \\
\mathrm{df}=8 \\
\mathrm{p}=0\end{array}$ \\
\hline $\begin{array}{c}\text { Do you have diagnosed } \\
\text { depression? } \\
\text { Yes } \\
\text { No }\end{array}$ & $\begin{array}{l}26(5.25 \%) \\
469 \\
(94.75 \%)\end{array}$ & $\begin{array}{l}45(15.79 \%) \\
240 \\
(84.21 \%)\end{array}$ & $\begin{array}{l}23(13.29 \%) \\
150 \\
(86.71 \%)\end{array}$ & $\begin{array}{l}27(24.32 \%) \\
84(75.68 \%)\end{array}$ & $\begin{array}{l}27(27.55 \%) \\
71(72.45 \%)\end{array}$ & $\begin{array}{c}\chi^{2}=58.27 \\
\mathrm{df}=4 \\
\mathrm{p}=0\end{array}$ \\
\hline
\end{tabular}

\section{Discussion}

In our study, the mean ACE score was 1.23, and the median ACE score was 1. In a study conducted by Sciolla et al. among 98 American third-year medical students the mean ACE score equaled 1.33, whereas a research conducted by Sheikh et al. among 260 Pakistani medical students this score equaled $1.37[13,14]$. In our analysis, $57.4 \%$ of the students suffered from at least one ACE, while in the above-mentioned studies the percentage was $51.2 \%$ and $52.6 \%$ respectively $[13,14]$. What is more, $8.43 \%$ of the participants of our study reported exposure to $\geq 4$ ACEs, while in the compared studies, it was $11.7 \%$ in a study by Sheikh et al. and $9.9 \%$ among Chinese medical students in a study by Xiao et al. $[13,15]$.

In our study, the most frequently reported ACEs were emotional abuse, experienced by $23.06 \%$ of the participants, followed by physical abuse $(22.98 \%)$, and mental illness or suicidal attempt in a household member (21.86\%). In a study by Sciolla AF et al., the most common ACEs were mental illness in a household member (29\%), followed by emotional abuse (21\%), and eq aequo sexual abuse and substance abuse in the household (15\%) [13]. In 
the study by Sheikh et al., the most commonly reported ACEs were also emotional (34.5\%) and physical abuse (22.0\%), while the third most common ACE was emotional neglect $(19.0 \%)$ [14]. On the other hand, in the study which investigated ACEs among Chinese medical students the most common ACE was physical neglect (26.9\%) followed by physical abuse (26.7), and mental illness in the household (23.0\%) [15].

Our analysis showed a link between higher Adverse Childhood Experiences score and a lower level of both maternal and paternal education. A similar link was described in a study conducted by Dorvil et al. in a sample of 2685 students of 7 diverse college/university students from the state of Georgia, USA. In that study, parental education at a level lower than a Bachelor degree was associated with higher ACEs scores among children [14]. Similarly, in an analysis carried out by Agbaje et al. among 330 students from the University of Nigeria and the School of Public Health Technology in Nigeria, where a lower level of parental education was significantly associated with both ACEs and exposure to psychological distress. According to the authors, parental education may play a role of a protective factor against Adverse Childhood Experiences and provides a buffer from poor health outcomes among children and adolescents [17]. Conversely, Karatekin et al. found no statistically significant links between parental education and ACEs among 321 American young adults [18].

In our study, higher ACE scores were significantly associated with negative relationships with both parents. In a large longitudinal study including 8658 Irish primary school students, Dhondtet al. showed that childhood adversities were significantly linked to parent-child conflicts, and what is more, that parent-child conflicts mediates the relationship between childhood adversity and psychopathology reported at age of 13 and persistent psychopathology between the age of 9 and 13 [19]. Similarly, McMahon et al. in their study carried out among 973 teenage students from 10 European countries, stated that parental support plays a protective role from childhood adversities and the development of psychotic symptoms [20].

Our research showed a link between negative relationships with siblings and higher ACEs scores. In case of an impact of childhood adversities on sibling relationships, two different hypotheses were presented [21, 22]. The compensation hypothesis suggests that adverse circumstances promote supportiveness and warmth in a sibling relationship. Conversely, the contamination hypothesis states that adverse circumstances undermine the sibling relationship. Ingram et al. in their study stated that children who witnessed family violence were more prone to fall into sibling aggression [22]. Interestingly, Bussemakers et al. in their study 
conducted among 3128 Dutch adults showed that compared to people with one sibling, people without siblings and people with 3 siblings were more likely to experience childhood adversity in their youth [23].

Our research also showed a statistically significant link between negative relationship with friends and higher ACE scores. Bellis et al. in their retrospective study including 2452 adults from Wales found that resilience assets (including supportive childhood friends and a trusted adult) were linked to better health outcomes. Interestingly, the perception of having supportive friends was strongly related to a lower prevalence of headaches [24]. In another study, Ashton et al. suggested that having a trusted adult is an important source of childhood resilience. They found that the prevalence of trusted adult access decreased with increasing ACE scores, from $86.6 \%$ of individuals with no ACEs to $44.4 \%$ among individuals with at least 4 ACEs. Additionally, they found that among participants with at least 4 ACEs, those who had access to a trusted adult were 5.6 times more likely to have supportive friends, compared to the participants who didn't have a trusted adult [25].

Taking the above-mentioned conclusions altogether, we suggest that an exposure to ACEs may be considered as a predictor of lack of social support. A similar conclusion was made by Karatekin et al. who found that among 321 American students, participants with higher ACE scores reported feeling less supported comparing to those with lower ACE scores [18]. Social support may also play a protective role from the development of mental health problems associated with ACEs. In one study, Baiden et al. showed that childhood adversities (including physical abuse and sexual abuse) were predictors of non-suicidal self-injury, whereas adversities associated with parents, such as the mental illness of a parent of domestic violence, were not predictors of self-injury. Authors also showed that children and adolescents who had some form of social support, had a $26 \%$ decrease in non-suicidal selfinjury risk, compared to children with a lack of social support [26].

In our analysis, we found a significant link between ACEs and having a diagnosis of depression. Similarly, in a study carried out by Amone-P'Olak et al. among 392 young adults in Botswana, ACEs were found to be a significant predictors of depression in young adulthood [27]. In a similar study, conducted among 401 Iraq young adults aged from 18 to 20 years, Shawi et al. found a link between depression and most types of ACEs. Depression was statistically significantly correlated with emotional abuse, emotional neglect, physical abuse, and physical neglect [28]. Lemon et al. in a study concerning factors linked to depressive symptoms among 666 racial and ethnic minority students of 7 diverse universities 
in the state of Georgia showed that Adverse Childhood Experiences were connected to more severe depressive symptoms. Interestingly, while such association was significant among Black and Latin students, it was not statistically significant in case of Asian students [29].

\section{Conclusions}

1. More than a half of the students (57.4\%) had at least 1 exposure to ACEs. $8.43 \%$ of them experienced 4 or more childhood adversities. The most commonly reported ACEs were: emotional neglect (23.06\%), emotional abuse (22.98\%) and mental illness or a suicide attempt in a household member $(21.86 \%)$.

2. An overall graded relationship was found between ACE score and: parents' lower level of education, negative relationship with parents, siblings and friends and having a diagnosis of depression.

3. Adverse Childhood Experiences are common among Polish medical and dental students and are associated with worsened social relationships and depression in their adult life. This problem requires more attention from clinical and academic environment. It is important to implement strategies that aim to prevent ACEs and help to build social support networks for those who are affected by them.

\section{References}

1. Barnes AJ, Anthony BJ, Karatekin $\mathrm{C}$ et al. Identifying adverse childhood experiences in pediatrics to prevent chronic health conditions. Pediatr Res. 2020 Jan;87(2):362-370. doi: 10.1038/s41390-019-0613-3. PMID: 31622974.

2. Thakur N, Hessler D, Koita K et al. Pediatrics adverse childhood experiences and related life events screener (PEARLS) and health in a safety-net practice. Child Abuse Negl. 2020 Oct;108:104685. doi: 10.1016/j.chiabu.2020.104685. PMID: 32898839.

3. Merrick MT, Ford DC, Ports KA et al. Vital Signs: Estimated Proportion of Adult Health Problems Attributable to Adverse Childhood Experiences and Implications for Prevention 
— 25 States, 2015-2017. MMWR Morb Mortal Wkly Rep. 2019 Nov 8; 68(44): 9991005. doi: 10.15585/mmwr.mm6844e1. PMID: 31697656.

4. McKelvey LM, Saccente JE, Swindle TM. Adverse Childhood Experiences in Infancy and Toddlerhood Predict Obesity and Health Outcomes in Middle Childhood. Child Obes. 2019 Apr 1; 15(3): 206-215. PMID: 30762431.

5. Kaufman J, Montalvo-Ortiz JL, Holbrook H et al. Adverse Childhood Experiences, Epigenetic Measures, and Obesity in Youth. J Pediatr. 2018 Nov;202:150-156.e3. doi: 10.1016/j.jpeds.2018.06.051. PMID: 30177354.

6. Subramaniam M, Abdin E, Vaingankar JA et al. Association of adverse childhood experiences with diabetes in adulthood: results of a cross-sectional epidemiological survey in Singapore. BMJ Open. 2021; 11(3): e045167. doi: 10.1136/bmjopen-2020-045167. PMID: 33722874.

7. Kidman R, Piccolo LR, Kohler HP. Adverse Childhood Experiences: Prevalence and Association With Adolescent Health in Malawi. Am J Prev Med. 2020 Feb;58(2):285-293. doi: 10.1016/j.amepre.2019.08.028. PMID: 31810632.

8. DeLisi M, Drury AJ, Elbert MJ. The etiology of antisocial personality disorder: The differential roles of adverse childhood experiences and childhood psychopathology. Compr Psychiatry. 2019 Jul;92:1-6. doi: 10.1016/j.comppsych.2019.04.001. PMID: 31079021.

9. Wiehn J, Hornberg C, Fischer F. How adverse childhood experiences relate to single and multiple health risk behaviours in German public university students: a cross-sectional analysis. BMC Public Health. 2018; 18: 1005. doi: 10.1186/s12889-018-5926-3. PMID: 30103728.

10. Houtepen LC, Heron J, Suderman MJ at al. Associations of adverse childhood experiences with educational attainment and adolescent health and the role of family and socioeconomic factors: A prospective cohort study in the UK. PLoS Med. 2020 Mar; 17(3): e1003031. doi: 10.1371/journal.pmed.1003031. PMID: 32119668. 
11. Merrick MT, Ford DC, Ports KA et al. Prevalence of Adverse Childhood Experiences From the 2011-2014 Behavioral Risk Factor Surveillance System in 23 States. JAMA Pediatr. 2018 Nov 1;172(11):1038-1044. doi: 10.1001/jamapediatrics.2018.2537. PMID: 30242348 .

12. Stork BR, Akselberg NJ, Qin Y et al. Adverse Childhood Experiences (ACEs) and Community Physicians: What We've Learned. Perm J. 2020; 24: 19.099. doi: 10.7812/TPP/19.099. PMID: 32069204.

13. Sciolla AF, Wilkes MS, Griffin EJ. Adverse Childhood Experiences in Medical Students: Implications for Wellness. Acad Psychiatry. 2019; 43(4): 369-374. doi: 10.1007/s40596019-01047-5. PMID: 30850989.

14. Haaris Sheikh M, Naveed S, Waqas A, Tahir Jaura I. Association of adverse childhood experiences with functional identity and impulsivity among adults: a cross-sectional study. F1000Res. 2017 Nov 8;6:1978. doi: 10.12688/f1000research.13007.2. PMID: 30228858; PMCID: PMC6117857.

15. Xiao Q, Dong MX, Yao J, Li WX, Ye DQ. Parental alcoholism, adverse childhood experiences, and later risk of personal alcohol abuse among Chinese medical students. Biomed Environ Sci. 2008 Oct;21(5):411-9. doi: 10.1016/S0895-3988(08)60062-8. PMID: 19133615.

16. Berg CJ. HHS Public Access. 2021;45(3):295-308.

17. Agbaje OS, Nnaji CP, Nwagu EN, Iweama CN, Umoke PCI, Ozoemena LE, Abba CC. Adverse childhood experiences and psychological distress among higher education students in Southeast Nigeria: an institutional-based cross-sectional study. Arch Public Health. 2021 Apr 29;79(1):62. doi: 10.1186/s13690-021-00587-3. Erratum in: Arch Public Health. 2021 Jun 10;79(1):98. PMID: 33926542; PMCID: PMC8086118. 
18. Karatekin C, Ahluwalia R. Effects of Adverse Childhood Experiences, Stress, and Social Support on the Health of College Students. J Interpers Violence. 2020 Jan;35(1-2):150172. doi: 10.1177/0886260516681880. Epub 2016 Dec 5. PMID: 27920360

19. Dhondt N, Healy C, Clarke M, Cannon M. Childhood adversity and adolescent psychopathology: evidence for mediation in a national longitudinal cohort study. Br $\mathrm{J}$ Psychiatry. 2019 Sep;215(3):559-564. doi: 10.1192/bjp.2019.108. PMID: 31094302.

20. McMahon EM, Corcoran P, Keeley H, Clarke M, Coughlan H, Wasserman D, Hoven CW, Carli V, Sarchiapone M, Healy C, Cannon M. Risk and protective factors for psychotic experiences in adolescence: a population-based study. Psychol Med. 2021 May;51(7):1220-1228. doi: 10.1017/S0033291719004136. Epub 2020 Feb 6. PMID: 32026792 .

21. Witte S, Fegert JM, Walper S. Sibling relationship pattern in the context of abuse and neglect: Results from a sample of adult siblings. Child Abuse Negl. 2020 Aug;106:104528. doi: 10.1016/j.chiabu.2020.104528. Epub 2020 May 29. PMID: 32480104.

22. Ingram KM, Espelage DL, Davis JP, Merrin GJ. Family Violence, Sibling, and Peer Aggression During Adolescence: Associations With Behavioral Health Outcomes. Front Psychiatry. 2020 Feb 11;11:26. doi: 10.3389/fpsyt.2020.00026. PMID: 32116843; PMCID: PMC7027165.

23. Bussemakers C, Kraaykamp G, Tolsma J. Co-occurrence of adverse childhood experiences and its association with family characteristics. A latent class analysis with Dutch population data. Child Abuse Negl. 2019 Dec;98:104185. doi: 10.1016/j.chiabu.2019.104185. Epub 2019 Sep 23. PMID: 31557674.

24. Bellis, Mark \& Hughes, Karen \& Ford, Kat \& Hardcastle, Katherine \& Sharp, Catherine \& Wood, Sara \& Homolova, Lucia \& Davies, Alisha. (2018). Adverse childhood experiences and sources of childhood resilience: A retrospective study of their combined 
relationships with child health and educational attendance. BMC Public Health. 18. 792. doi: 10.1186/s12889-018-5699-8.

25. Ashton K, Davies AR, Hughes K, Ford K, Cotter-Roberts A, Bellis MA. Adult support during childhood: a retrospective study of trusted adult relationships, sources of personal adult support and their association with childhood resilience resources. BMC Psychol. 2021 Jun 27;9(1):101. doi: 10.1186/s40359-021-00601-x. PMID: 34176519; PMCID: PMC8237477.

26. Baiden P, Stewart SL, Fallon B. The role of adverse childhood experiences as determinants of non-suicidal self-injury among children and adolescents referred to community and inpatient mental health settings. Child Abuse Negl. 2017 Jul;69:163-176. doi: 10.1016/j.chiabu.2017.04.011. Epub 2017 May 3. PMID: 28477476.

27. Amone-P'Olak K, Letswai NK. The relationship between adverse childhood experiences and depression: A cross-sectional survey with university students in Botswana. S Afr J Psychiatr. 2020 Nov 3;26:1444. doi: 10.4102/sajpsychiatry.v26i0.1444. PMID: 33240547; PMCID: PMC7669992.

28. Al Shawi AF, Sarhan YT, Altaha MA. Adverse childhood experiences and their relationship to gender and depression among young adults in Iraq: a cross-sectional study. BMC Public Health. 2019 Dec 16;19(1):1687. doi: 10.1186/s12889-019-7957-9. PMID: 31842837; PMCID: PMC6916082.

29. Lemon ED, Vu M, Roche KM, Hall KS, Berg CJ. Depressive Symptoms in Relation to Adverse Childhood Experiences, Discrimination, Hope, and Social Support in a Diverse Sample of College Students. J Racial Ethn Health Disparities. 2021 Apr 9. doi: 10.1007/s40615-021-01038-z. Epub ahead of print. PMID: 33835419. 